\title{
Assédio moral no trabalho: aspectos conceituais, jurídicos e preventivos*
}

\section{Psychological harrassment at work conceptual, legal and preventive aspects}

\author{
Débora Miriam Raab Glina1, Andréia de Conto Garbin²
}

Glina DMR, Garbin A de C. Assédio moral no trabalho: aspectos conceituais, jurídicos e preventivos. Saúde, Ética \& Justiça, São Paulo. 2005;10(1/2):38-47.

RESUMO: Objetivo: Abordar o assédio moral no trabalho em seus aspectos conceituais, jurídicos e preventivos. Metodologia: Em 2004 foi realizado um levantamento de todas as publicações científicas nacionais sobre o assédio moral no âmbito jurídico: livros, artigos publicados em periódicos indexados ou não em bases de dados como o SciELO e Lilacs cobrindo o período de 2000 a 2004, jurisprudências e leis. Os aspectos conceituais e preventivos foram obtidos em publicações da Organização Mundial da Saúde (OMS), Organização Internacional do Trabalho (OIT), Agência Européia de Saúde e Segurança no Trabalho, entre outros. Resultados e discussão: Não há uma definição única de assédio moral acordada mundialmente. $O$ assédio moral pode ser vertical, horizontal ou ascendente. Ele caracteriza-se por ser uma violência continuada que visa excluir a vítima do mundo do trabalho. As situações de trabalho que favorecem a ocorrência de assédio moral incluem: o estilo de gerenciamento, problemas ligados à organização do trabalho e os resultantes da flexibilização da produção. $O$ assédio moral pode causar ou contribuir para muitas desordens. Os diagnósticos mais comuns associados a situações de assédio moral no trabalho são depressão e desordens ansiosas, mas também ocorrem o transtorno de ajustamento e o transtorno do estresse póstraumático. A doutrina jurídica relaciona o assédio moral à teoria da responsabilidade civil, tanto ao dano material quanto ao dano moral. No âmbito Federal, há projetos de leis que tramitam no Congresso Nacional, com o objetivo de regular a questão do assédio moral na esfera Penal. Outras propostas legislativas federais que versam sobre assédio moral reformam o regime jurídico dos servidores públicos da União e alteram a Lei de Licitações Públicas. Não obstante a promulgação de diversas leis, sejam elas estaduais ou municipais, sua aplicabilidade, na maioria das vezes, atinge os órgãos, repartições ou entidades da administração pública, autarquias, fundações, empresas públicas ou sociedades de economia mista. Além disso, estas leis abordam apenas o assédio moral vertical (do chefe para o subordinado). Com relação à prevenção parte-se da identificação dos fatores favorecedores do assédio moral. Ela se baseia na participação e cooperação de todas as partes envolvidas. A prevenção pode ser primária, secundária ou terciária.

DESCRITORES: Comportamento social/prevenção e controle. Ambiente de trabalho/legislação \& jurisprudência. Ambiente de trabalho/psicologia. Dano moral. Responsabilidade civil. Trabalho/psicologia. Trabalho/ética. Estresse psicológico. Saúde ambiental/ética.

\footnotetext{
* Artigo baseado em monografia de Andréia De Conto Garbin, defendida em 2004 e orientada pelo Prof. Dr. Mauro Luis lasi, Faculdade de Direito de São Bernardo do Campo.

1 Psicóloga, Doutora em Psicologia Social e Ergonomista. Departamento de Medicina Legal, Ética Médica e Medicina Social e do Trabalho, Faculdade de Medicina, Universidade de São Paulo.

2 Psicóloga. Secretaria Estadual de Saúde, Governo do Estado de São Paulo.

Endereço para correspondência: Rua Teodoro Sampaio, 115. CEP 057405-000. São Paulo, SP. e-mail: deboraglina@uol.com.br
} 


\section{INTRODUÇÃO}

O assédio moral, também conhecido como bullying, mobbing, psychological harassment, emotional abuse, bossing, victimization, psychological violence, harcèlement moral, harcèlement psychologique, assédio no local de trabalho, acoso moral, entre outros, é um fenômeno que vem crescendo no mundo todo.

De acordo com Di Martino ${ }^{7}$ ele aparece em $30,9 \%$ dos respondentes na Bulgária, 20,6\% na África do Sul, $10,7 \%$ na Tailândia, 22,1\% no Líbano, $10,5 \%$ na Austrália e $15,2 \%$ no Brasil.

De acordo com o 3 o levantamento das condições de trabalho um em cada 10 trabalhadores referiram estar sendo sujeitados à intimidação no local de trabalho em 2000 ${ }^{14}$. Segundo a Organização Internacional do Trabalho ${ }^{13}$, na União Européia cerca de $9 \%$ dos trabalhadores -13 milhões de pessoas convivem com o tratamento tirânico de seus patrões e superiores.

No Brasil vem ocorrendo a proliferação de situações de assédio moral no trabalho. Esse fato tem dado origem a diversas demandas judiciais. Essas ações deparavam-se com a dificuldade de não existir a figura jurídica do assédio moral no trabalho, hoje existente no âmbito estadual e municipal. De modo geral, as ações se amparam na Constituição Federal, nos Direitos Fundamentais, na garantia da dignidade da pessoa humana. Visando suprir essa lacuna, vem sendo propostos projetos de lei e legislações sobre o tema.

Traçar um panorama dessas legislações e projetos de leis foi objetivo deste estudo. Além disso, buscou-se apresentar os aspectos conceituais mais relevantes sobre assédio moral no trabalho e as discussões sobre a sua prevenção.

\section{METODOLOGIA}

Em 2004 foi realizado um levantamento de todas as publicações científicas nacionais sobre o assédio moral no âmbito jurídico: livros, artigos publicados em periódicos indexados em bases de dados como o SciELO e Lilacs cobrindo o período de 2000 a 2004, artigos publicados em periódicos não indexados, jurisprudências e leis.

Os aspectos conceituais e preventivos foram obtidos em publicações da Organização Mundial da Saúde (OMS), Organização Internacional do Trabalho (OIT), Agência Européia de Saúde e Segurança no Trabalho, entre outros.

\section{RESULTADOS E DISCUSSÃO}

\section{Aspectos conceituais}

Não há uma definição única de assédio moral acordada mundialmente.

Leymann ${ }^{11}$, pioneiro no assunto, conceitua o assédio moral como: "A deliberada degradação das condições de trabalho através do estabelecimento de comunicações não éticas (abusivas), que se caracterizam pela repetição, por longo tempo, de um comportamento hostil de um superior ou colega(s) contra um indivíduo que apresenta, como reação de um quadro de miséria física, psicológica e social duradoura".

Para Hirigoyen ${ }^{9} \mathrm{o}$ assédio moral no trabalho é toda e qualquer conduta abusiva manifestando-se, sobretudo por comportamentos, palavras, atos, gestos, escritos que possam trazer dano à personalidade, à dignidade ou à integridade física ou psíquica de uma pessoa, pôr em perigo seu emprego ou degradar o ambiente de trabalho.

Barreto $^{2}$ define o assédio ou violência moral como aquele que acontece dentro do local de trabalho, ao longo da jornada, de forma repetitiva contra o trabalhador, colocando-o numa situação constrangedora, vexatória por parte do superior hierárquico. Segundo a autora ele caracteriza-se por relações desumanas, anti-éticas. O outro não é considerado igual em direitos. O objetivo principal do agressor é desqualificar o outro, enquanto profissional e como pessoa.

Para a European Agency for Safety and Health at $W_{o r k}{ }^{8}$ o assédio moral no trabalho é o comportamento repetido, não razoável contra um empregado ou grupo de empregados, que cria riscos para a saúde e segurança. Nessa definição o comportamento não razoável é conceituado como aquele que vitimiza, humilha, diminui ou ameaça. Comportamento é entendido como ações de indivíduos ou grupos, sistemas de trabalho usados com a finalidade de vitimizar, humilhar, diminuir ou ameaçar. O risco para a saúde e segurança inclui os riscos à saúde física e mental do empregado.

$\mathrm{O}$ assédio moral caracteriza-se como uma violência multilateral: pode ser vertical, horizontal ou ascendente. $O$ agressor é freqüentemente, mas não necessariamente, o chefe. Segundo Hirigoyen ${ }^{9}$ o assédio moral pode provir do comando hierárquico (vertical), de colegas da mesma hierarquia funcional (horizontal), da omissão do superior hierárquico diante de uma agressão (descendente), ou caso raro, quando o poder, por alguma razão, não está com o comando superior e sim nas mãos do subalterno 
(ascendente). Mas quem detém o poder pode mais facilmente abusar dele, quando, no nível gerencial, são estimulados comportamentos e atitudes de abuso de poder, mau gerenciamento e descumprimento de normas e acordos.

Para Hirigoyen ${ }^{9}$ e Menezes ${ }^{12}$ a exteriorização do assédio moral ocorre através de gestos, agressões verbais, comportamentos obsessivos e vexatórios, humilhações públicas e privadas, amedrontamento, ironias, sarcasmos, coações públicas, difamações, exposição ao ridículo (tarefas degradantes ou abaixo da capacidade profissional, sorrisos, suspiros, trocadilhos, jogo de palavras de cunho sexista, indiferença à presença do outro, silêncio forçado, trabalho superior às forças do empregado, sugestão para pedido de demissão, ausência de serviço e tarefas impossíveis ou de dificílima realização, controle do tempo no banheiro, divulgação pública de detalhes íntimos, agressões e ameaças, olhares de ódio, instruções confusas, referências a erros imaginários, solicitação de trabalhos urgentes para depois jogá-los no lixo ou na gaveta, imposição de horários injustificados, isolamento no local de trabalho; transferência de sala por mero capricho; retirada de mesa de trabalho e pessoal de apoio, boicote de material necessário à prestação de serviços e supressão de funções).

$O$ assédio moral caracteriza-se por ser uma violência continuada que visa excluir a vítima do mundo do trabalho, seja forçando-a a demitir-se, a aposentar-se precocemente ou a licenciar-se para tratamento de saúde.

O estilo específico de agressão varia de acordo com os meios socioculturais e profissionais. Nos setores de produção, a violência é mais direta, verbal ou física. Por outro lado, quanto mais se sobe na hierarquia e na escala social, mais as agressões são sofisticadas, perversas e difíceis de caracterizar.

Mais importante do que discutir uma tipologia do assediador e do assediado é discutir as situações de trabalho que aumentam o risco de ocorrência de assédio moral.

Para Cassito et al. ${ }^{6}$ o estilo de gerenciamento disciplinar, intolerante e discriminatório cria um clima de medo, desconfiança e competição excessiva. A falta de normas sobre o comportamento social pode fazer com que certas pessoas se sintam autorizadas a usar comportamento abusivo. Formas de gerenciamento que estimulem a competição, incluindo certos instrumentos gerenciais como a avaliação de desempenho ou promoção por mérito têm o potencial de gerar suspeita e uma atmosfera negativa.

Problemas ligados à organização do trabalho como falta crônica de pessoal, constrangimentos de trabalho, tarefas mal definidas, excesso de hierarquia, instruções insuficientes ou falta de informação são favorecedores de assédio moral.

A flexibilização da produção, o downsizing e a reestruturação produtiva podem resultar na precarização do trabalho e no medo de perder o emprego. A terceirização e a multiplicação de subsidiárias com traços culturais diferentes podem produzir situações que levam à negligência de características humanas e locais dos empregados. Todas essas são situações que podem favorecer o assédio moral.

$O$ assédio moral difere de outros tipos de conflito porque é caracterizado por ações anti-éticas. Em situações de assédio: o clima de trabalho é pesado, a comunicação é ambígua e a interação hostil.

\section{Efeitos na saúde}

Para Cassito et al. ${ }^{6}$ o assédio moral tem o potencial de causar ou contribuir para muitas desordens. Não se sabe quantas vítimas de assédio moral desenvolvem problemas de saúde. Isso provavelmente depende da duração e intensidade dos estressores. A personalidade da vítima também pode ter um papel protetor ou favorecedor. Os sintomas podem ser psicopatológicos, psicossomáticos ou comportamentais.

Os sintomas psicopatológicos incluem: reações de ansiedade, apatia, reações de esquiva, problemas de concentração, humor deprimido, reações de medo, flashbacks, hiperexcitabilidade, insônia, insegurança, irritabilidade, mudanças de humor, pesadelos recorrentes, pensamentos intrusivos, falta de iniciativa, melancolia, labilidade afetiva.

Dentre os sintomas psicossomáticos podem ser citados: hipertensão arterial, ataques de asma, palpitações, distúrbio coronariano, dermatite, perda de cabelos, cefaléia, dores musculares e articulares, perda de equilíbrio, enxaqueca, epigastralgia, úlceras estomacais e taquicardia.

Os sintomas comportamentais incluem: reações auto e heteroagressivas, distúrbios alimentares, aumento no consumo de álcool e outras drogas, aumento no tabagismo, disfunções sexuais e isolamento social.

O estudo de Barreto ${ }^{2}$ com 870 homens e mulheres vítimas de opressão no ambiente profissional revelou a existência de diferenças nos sintomas entre os trabalhadores e as trabalhadoras. Embora certos sintomas sejam comuns aos dois sexos, como dores generalizadas, distúrbios de sono e depressão, existem sintomas específicos de cada sexo (por exemplo, crises de choro no sexo feminino e tentativa de suicídio no sexo masculino) e outros que ocorrem com maior freqüência em um sexo do

Saúde, Ética \& Justiça, São Paulo. 2005;10(1/2):38-47. 
que no outro (por exemplo, tonturas, idéias de suicídio, consumo de bebidas alcoólicas, distúrbios digestivos, tonturas, palpitações) (Quadro 1).

Quadro 1 - Diferença de sintomas no ambiente profissional entre os trabalhadores e trabalhadoras.

\begin{tabular}{l|c|c}
\hline SINTOMAS & MULHERES & HOMENS \\
\hline Crises de choro & 100 & - \\
Dores generalizadas & 80 & 80 \\
Palpitações, tremores & 80 & 40 \\
Insônia ou sonolência & & \\
excessiva & 69,6 & 63,6 \\
Depressão & 60 & 70 \\
Diminuição da libido & 60 & 15 \\
Sede de vingança & 50 & 100 \\
Aumento da pressão & & \\
arterial & 40 & 51,6 \\
Dor de cabeça & 40 & 33,2 \\
Distúrbios digestivos & 40 & 15 \\
Tonturas & 22,3 & 3,2 \\
Idéia de suicídio & 16,2 & 100 \\
Problemas com bebida & 5 & 63 \\
Tentativa de suicídio & - & 18,3 \\
\hline Fonte: Barto, 2000. &
\end{tabular}

Fonte: Barreto, 2000.

Ao analisar a manifestação dos sentimentos e emoções nas situações de humilhação e constrangimentos são identificadas diferenças segundo o sexo: enquanto as mulheres expressam sua indignação com choro, tristeza, ressentimentos e mágoas, estranhando o ambiente que identificavam como seu, os homens sentem-se revoltados, indignados, desonrados, com raiva, traídos e têm vontade de vingar-se. Sentem-se envergonhados diante da mulher e dos filhos, sobressaindo o sentimento de inutilidade, fracasso e baixa autoestima. Isolam-se da família, evitam contar o acontecido aos amigos, passando a vivenciar sentimentos de irritabilidade, vazio, revolta e fracasso.

Os diagnósticos mais comuns associados a situações de assédio moral no trabalho são depressão e desordens ansiosas, mas outros diagnósticos são freqüentemente estabelecidos como o transtorno de ajustamento e o transtorno do estresse pós-traumático. O diagnóstico de transtorno de estresse pós-traumático é questionado por alguns psiquiatras porque implica um evento agudo e altamente traumático, enquanto o assédio moral geralmente se caracteriza por uma situação negativa prolongada. Assim, alguns pesquisadores têm proposto um diagnóstico suplementar de desordem compulsiva prolongada de estresse (prolonged duress stress disorder) ${ }^{15}$.

\section{Aspectos jurídicos}

A doutrina relaciona o assédio moral à teoria da responsabilidade civil, segundo a qual um sujeito de direito tem a obrigação de reparar o prejuízo causado a alguém como conseqüência da violação de um direito. O pressuposto essencial do dever de reparar é a existência de dano, este definido por Casillo ${ }^{5}$ como "o resultado da ofensa feita por terceiro a um direito, patrimonial ou não, que confere ao ofendido, como conseqüência, a pretensão a uma indenização".

Importa a apreciação do conceito de dano não patrimonial, doutrinariamente denominado dano moral, pois afeta a honra e causa lesão aos direitos no âmbito pessoal. Na Constituição Federal vigente, a proteção e a reparação do dano estão expressas no artigo 5, $\mathrm{V}$ e $\mathrm{X}$, nos seguintes termos: "é assegurado o direito de resposta, proporcional ao agravo, além da indenização por dano material, moral ou à imagem", e "são invioláveis a intimidade, a vida privada, a honra e a imagem das pessoas, assegurado o direito à indenização pelo dano material ou moral decorrente de sua violação". Ainda, a "dignidade da pessoa humana" é um dos fundamentos do país, conforme se verifica no artigo $1^{\circ}$, III, do diploma citado.

Silva ${ }^{16}$ (2004) ao estudar o dano moral na relação trabalhista assegura que o empregado tem direito à intimidade, à honra e à imagem nas relações de trabalho, sendo que cada qual é autônomo. No que tange à relação contratual entre empregado e empregador, a possibilidade de prática de ato lesivo da honra e boa fama contra o empregado dá margem ao ressarcimento dos danos morais.

A proteção à dignidade do trabalhador inscreve-se e faz parte do conteúdo necessário do contrato de trabalho, deste modo, proíbe a Constituição Federal $^{4}$ qualquer forma de discriminação e declara, em seu artigo 5, que "todos são iguais perante a Lei”.

É certo afirmar que o dano moral sofrido pelo empregado pode resultar ainda de atentado a vida, a integridade física ou a saúde do ser humano decorrentes de acidentes de trabalho ou doenças profissionais e do trabalho.

Consoante com o exposto, cumpre anotar que a doutrina modernamente prevê o dano moral nas situações de assédio moral. A relevância jurídica decorre da ilícita finalidade de discriminar, marginalizar ou, de qualquer outro modo, prejudicar o trabalhador.

Para Menezes ${ }^{12}$ o mais importante efeito jurídico do assédio moral "é a possibilidade de gerar reparação dos danos patrimoniais e morais pelos gravames de ordem econômica (perda do emprego, 
despesas com médicos, psicólogos...) e na esfera da honra, da boa fama, do auto-respeito e da saúde psíquica e física, da auto-estima”. Ressalta, ainda, que o assédio moral permite a rescisão indireta do contrato de trabalho, o afastamento por doença do trabalho e quando relacionado à demissão, a sua reintegração no emprego por nulidade absoluta do ato jurídico.

\section{Legislação e jurisprudência}

Diversos países têm incorporado o assédio moral em seu ordenamento jurídico. A legislação pioneira sobre o assédio ou coação moral é da Noruega que, em sua regulamentação trabalhista, de 1977, proíbe o assédio em geral.

Em termos de projetos, ou até mesmo à promulgação de leis, podemos destacar os seguintes países: Suécia, Alemanha, Itália, Austrália, Uruguai, Inglaterra, Suíça, Bélgica, Portugal, França, Japão e Estados Unidos.

No Brasil, no âmbito Federal, há projetos de leis tramitam no Congresso Nacional, com o objetivo de regular a questão do assédio moral na esfera Penal, dispondo sobre o crime de assédio moral no trabalho e coação moral, e na esfera trabalhista, refere-se à prática de coação moral pelo empregador ou seus prepostos.

Outras propostas legislativas federais que versam sobre assédio moral reformam o regime jurídico dos servidores públicos da União e alteram a Lei de Licitações Públicas. No primeiro caso, proibindo os atos de assédio moral contra subordinados. No segundo caso, instituindo o Cadastro Nacional de Proteção Contra a Coação Moral no Emprego.

No âmbito dos estados brasileiros, a primeira lei aprovada foi no Estado do Rio de Janeiro, no 3921, de 23 de agosto de 2002, que "veda o assédio moral no trabalho, no âmbito dos órgãos, repartições ou entidades da administração centralizada, autarquias, fundações, empresas públicas e sociedades de economia mista, do poder legislativo, executivo ou judiciário do Estado do Rio de Janeiro, inclusive concessionárias e permissionárias de serviços estaduais de utilidade ou interesse público, e dá outras providencias". Mais recentemente, o Estado de São Paulo, aprovou a lei n. 12.250, de 09 de fevereiro de 2006, que "veda o assédio moral no âmbito da administração pública estadual direta, indireta e fundações públicas"3.

Intensa produção de leis sobre o tema tem ocorrido no âmbito dos poderes legislativos municipais. A primeira legislação sobre o assédio moral foi na cidade de Iracemápolis, SP, de 24 de abril de 2000, Lei nำ1163/2000, dispõe sobre a aplicação de penalidades à prática de assédio moral nas dependências da Administração Pública Municipal Direta por servidores públicos municipais.

O Quadro 2 apresenta uma síntese das leis e projetos de lei sobre assédio moral existentes nos âmbitos Federal, Estadual e Municipal ${ }^{10}$.

Não obstante a promulgação de diversas leis, sejam elas estaduais ou municipais, ressalta-se que a sua aplicabilidade, na maioria das vezes, atinge os órgãos, repartições ou entidades da administração pública, autarquias, fundações, empresas públicas ou sociedades de economia mista. Além disso, estas leis abordam apenas o assédio moral vertical (do chefe para o subordinado).

Em relação às primeiras jurisprudências sobre o assédio moral no Brasil, destaca-se o julgamento inédito do Tribunal Regional do Trabalho da $17^{\text {a }}$ Região - Espírito Santo, que utilizou a denominação assédio moral ao negar provimento de recurso ao litigante - acórdão de número 2276/2001, 20 de agosto de 2002, relatora Juíza Sônia das Dores Dionísio.

\section{Aspectos preventivos}

Para Cassito et al. ${ }^{6}$ primeiramente precisariam ser identificados os fatores organizacionais que favorecem $o$ assédio. A efetividade de qualquer prevenção ao assédio baseia-se na participação e cooperação de todas as partes envolvidas (profissionais de saúde, dirigentes, gerentes, profissionais de Recursos Humanos, comunidade legal, sindicatos e trabalhadores).

Para os autores, a prevenção primária envolve o treinamento e informação dos gerentes e staff. Os trabalhadores deveriam ser informados sobre o assédio. Os gerentes deveriam ser treinados em resolução de conflitos. Campanhas de conscientização poderiam ser implementadas. Além disso, uma política contra o assédio deveria ser desenvolvida.

Para tanto, seria necessária a produção de guias e códigos de ética visando encorajar o comportamento ético. Os guias deveriam conter informações sobre a natureza e extensão do problema, bem como, seus efeitos na saúde e na qualidade de vida. $O$ código de ética deveria indicar claramente que a organização não tolera atos antiéticos e discriminação.

Os próprios contratos de trabalho ou prestação de serviços deveriam ter cláusulas regulando a matéria e prevendo sanções para qualquer quebra de normas.

Saúde, Ética \& Justiça, São Paulo. 2005;10(1/2):38-47. 
Quadro 2 - Leis aprovadas e projetos de lei sobre assédio moral.

\begin{abstract}
Lei de Âmbito Federal
Projeto de reforma do Código Penal, sobre assédio moral

Introduz artigo 146-A, no Código Penal Brasileiro - Decreto-lei no 2848, de 7

de dezembro de 1940 , dispondo sobre o crime de assédio moral no trabalho.

Projeto de reforma do Código Penal, sobre coação moral

Altera dispositivos do Decreto-Lei no 2.848 , de 7 de dezembro de 1940 - Código Penal.

Projeto de reforma da Lei $\mathrm{n}^{\circ} \mathbf{8 . 1 1 2}$, sobre assédio moral

Dispõe sobre a aplicação de penalidades à prática de "assédio moral" por parte de

servidores públicos da União, das autarquias e das fundações públicas federais

a seus subordinados, alterando a Lei no 8.112 , de 11 de dezembro de 1990 .

Projeto de reforma da Lei $\mathbf{n}^{\circ} \mathbf{8 . 1 1 2}$, sobre coação moral

Altera dispositivos da Lei no 8.112, de 11 de dezembro de 1990, que "Dispõe sobre o

Regime Jurídico dos Servidores Públicos Civis da União, das Autarquias e das

Fundações Públicas Federais".

Projeto de reforma da Lei $\mathbf{n} \mathbf{8} \mathbf{8 . 6 6 6}$, sobre coação moral

Altera dispositivos da Lei no 8.666, de 21 de junho de 1993, que "regulamenta o

artigo 37, inciso XXI, da Constituição Federal, institui normas para licitações e contratos

da Administração Pública e dá outras providências", e institui o CADASTRO NACIONAL

DE PROTEÇÃO CONTRA A COAÇÃO MORAL NO EMPREGO.

Projeto de reforma do Decreto-Lei no 5.452 , sobre coação moral

Altera dispositivos do Decreto-Lei $n^{\circ}$ 5.452, de $1^{\circ}$ de maio de 1943 - Consolidação das

Leis do Trabalho (CLT).
\end{abstract}

\section{Legislação de Âmbito Estadual}

Lei contra assédio moral do Estado do Rio de Janeiro

Veda o assédio moral no trabalho, no âmbito dos órgãos, repartições ou entidades

da administração centralizada, autarquias, fundações, empresas públicas e sociedades de economia mista, do poder legislativo, executivo ou judiciário do Estado do Rio de Janeiro, inclusive concessionárias e permissionárias de serviços estaduais de utilidade ou interesse público, e dá outras providencias.

Lei veda o assédio moral no âmbito da Administração Pública no Estado de São Paulo Veda o assédio moral no âmbito da administração pública estadual direta, indireta e fundações públicas.

Projeto de lei na Assembléia Legislativa do Estado da Bahia

Dispõe sobre o assédio moral no âmbito da administração pública estadual direta,

indireta, fundacional e autárquica e dá outras providências.

Projeto de lei na Assembléia Legislativa do Estado do Ceará

Veda o assédio moral no trabalho, no âmbito dos órgãos, repartições ou entidades da administração centralizada, autarquias, fundações, empresas públicas e sociedades de economia mista, do poder legislativo, executivo ou judiciário do Estado do Rio de Janeiro, inclusive concessionárias e permissionárias de serviços estaduais de utilidade ou interesse público, e dá outras providencias.

Projeto de lei na Assembléia Legislativa do Estado do Espírito Santo Veda o assédio moral no âmbito da administração pública estadual, direta, indireta e fundacional, e dá outras providências.

Projeto de lei na Assembléia Legislativa do Estado de Pernambuco Fica vedada a prática de assédio moral no âmbito da Administração pública estadual direta e indireta de qualquer de seus poderes e fundações públicas.

Projeto de lei na Assembléia Legislativa do Estado do Rio Grande do Sul Dispõe sobre o assédio moral no âmbito da administração pública estadual, e dá outras providências.

\section{№ da Lei}

Projeto de lei federal $n$ ㅇ 4742/2001

Projeto de lei federal no 5.971/2001

Projeto de lei federal no 4591/2001

Projeto de lei federal $n^{\circ}$ 5.972/2001

Projeto de lei federal $\mathrm{n}^{\circ} 6.161 / 2002$

Arquivado em 03/08/2004

Projeto de lei federal n 5.970/2001

№ da Lei

Lei $n^{\circ}$ 3921, de 23/08/2002

Lei $n^{\circ} 12.250$ de 09/02/2006

Projeto de lei no $12.819 / 2002$

Projeto de lei $\mathrm{n}^{\circ}$ $/ 2003$

Projeto de lei no 128/2002

Projeto de lei complementar $\mathrm{n}^{\circ}$ 
Glina DMR, Garbin A de C. Assédio moral no trabalho: aspectos conceituais, jurídicos e preventivos.

Quadro 2 - Leis aprovadas e projetos de lei sobre assédio moral. (continuação)

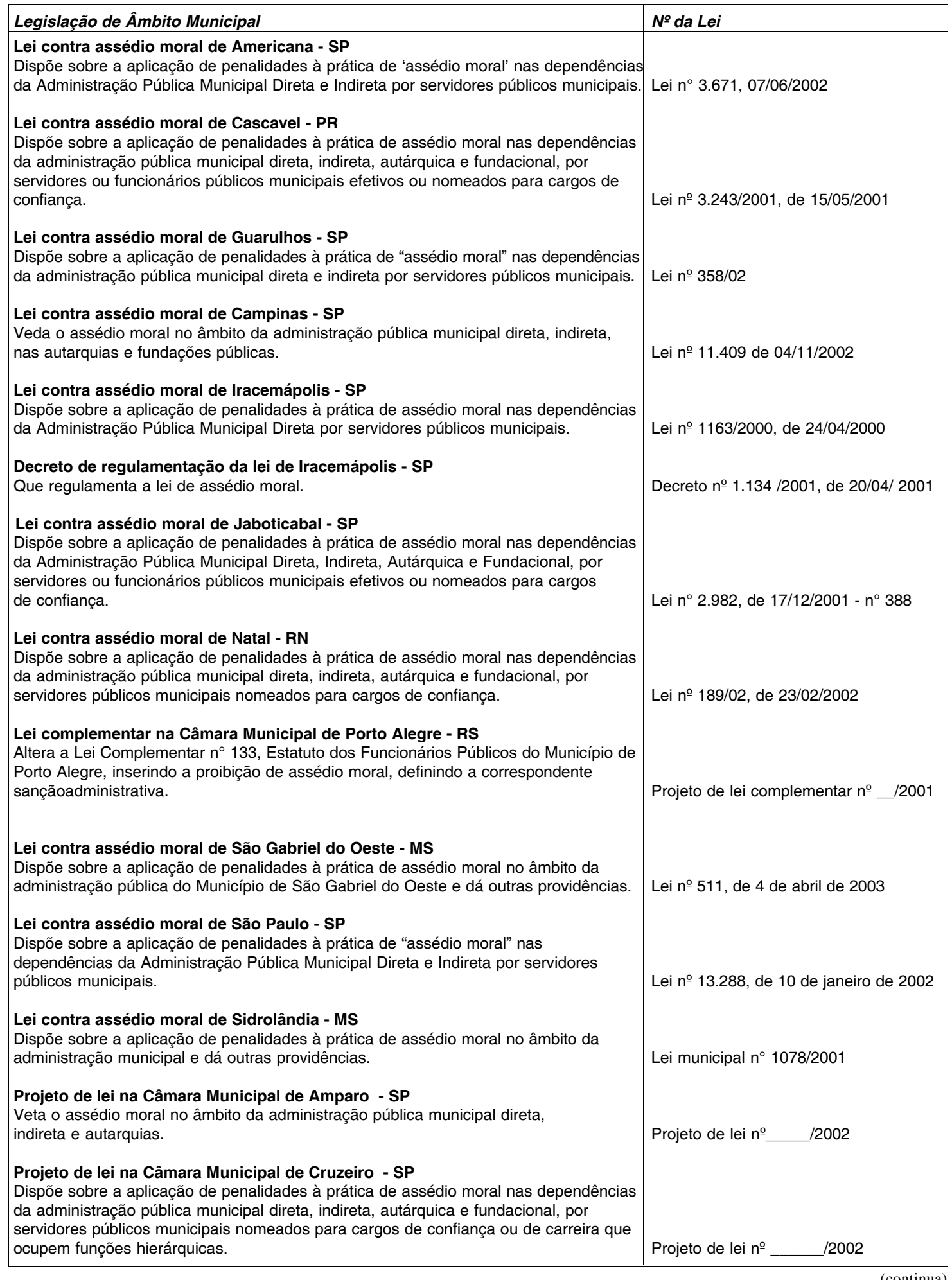


Quadro 2 - Leis aprovadas e projetos de lei sobre assédio moral. (continuação)

Projeto de lei na Câmara Municipal de Curitiba - PR

Dispõe sobre a aplicação de penalidades à prática de "assédio moral" nas dependências da Administração Pública Municipal Direta e Indireta por servidores públicos municipais.

Projeto de lei $\mathrm{n}^{\circ}$ $/ 2001$

Projeto de lei na Câmara Municipal de Guararema - SP

Dispõe sobre a caracterização do ASSÉDIO MORAL nas dependências da administração pública municipal, e aplicação de penalidades à prática do mesmo, e dá outras providências.

Projeto de lei na Câmara Municipal de Guaratinguetá - SP

Dispõe sobre a aplicação de penalidades à prática de assédio moral nas dependências da administração pública municipal direta, indireta, autárquica e fundacional, por servidores ou funcionários públicos municipais efetivos ou nomeados para cargos em comissão ou de confiança.

Projeto de lei na Câmara Municipal de Reserva do Iguaçu - RS

Dispõe sobre a aplicação de penalidades à prática de assédio moral nas dependências da administração pública municipal direta, indireta, autárquica e fundacional, por servidores ou funcionários públicos municipais efetivos ou nomeados para cargos em comissão ou de confiança.

Projeto de lei na Câmara Municipal de Presidente Venceslau - SP Dispõe sobre a aplicação de penalidades à prática de "assédio moral" nas dependências da Administração Pública Municipal Direta e Indireta por servidores públicos municipais.

Projeto de lei na Câmara Municipal de Ribeirão Pires - SP

Dispõe sobre a aplicação de penalidades à prática de assédio moral nas dependências da Administração Pública Municipal Direta.

Projeto de lei na Câmara Municipal de São José dos Campos - SP Dispõe sobre a caracterização do ASSÉDIO MORAL nas dependências da administração pública municipal, e aplicação de penalidades à prática do mesmo, e dá outras providências.

Projeto de lei na Câmara Municipal de Vitória - ES

Dispõe sobre a aplicação de penalidades à prática de assédio moral nas dependências da administração pública municipal direta, indireta, autárquica e fundacional, por servidores municipais

Fonte: http://www.assédiomoral.org

Uma vez que um processo de assédio tenha começado, pode tornar-se difícil controlá-lo, a menos que medidas imediatas e efetivas sejam tomadas.

Um confidente ou ouvidor, interno ou externo à organização, poderia receber a incumbência de ouvir qualquer pessoa que se considere uma vítima de assédio. O próprio reconhecimento do problema da pessoa é essencial para quebrar a negação que freqüentemente encobre a agressão. Permite também, que a pessoa clarifique sua experiência, distancie-se da situação e tome iniciativas para parar a agressão.

Um mediador poderia oferecer às pessoas envolvidas no conflito a oportunidade de se compreenderem, analisar o ocorrido e negociar uma solução.

Dadas as sérias conseqüências à saúde do assédio, o diagnóstico precoce se torna importante.
A criação de um grupo de apoio, constituído por pessoas que sofreram assédio moral em diferentes situações permite o compartilhamento de experiências, a conscientização de que a pessoa não é responsável pelo evento, o reconhecimento da agressão e a modificação de comportamentos.

Segundo Yamada ${ }^{17}$ a legislação deveria endereçar os seguintes aspectos: encorajar medidas preventivas para reduzir a ocorrência de assédio moral no trabalho; proteger os trabalhadores que denunciam o assédio e providenciar incentivos para os empregadores que respondem com presteza, justiça e efetividade; fornecer alívio apropriado para os alvos de assédio severo, incluindo a compensação de danos e, quando aplicável, a reintegração no mesmo cargo; punir o assédio e os empregadores que permitem o abuso.

Com o intuito de inibir condutas abusivas no 
trabalho e considerando a falta de uma legislação específica sobre o tema, verifica-se que as Convenções e Acordos Coletivos, no âmbito das negociações coletivas, poderão ser instrumentos eficazes para definição de medidas destinadas a evitar a prática do assédio moral. Ainda, que o Ministério Público e entidades sindicais podem propor a ação civil pública para assegurar o interesse coletivo ou individual homogêneo'.

Referente a criminalização do assédio moral, embora alguns autores apontem como fundamental para o combate a sua prática, tal como aconteceu com o assédio sexual, deparamo-nos com escassa produção a respeito do tema.

$\mathrm{O}$ empregador que estimula, permite ou é omisso quanto às práticas do assédio moral no trabalho deverá responder pelos danos morais resultantes.

Outro aspecto relevante refere-se aos agravos à saúde decorrentes das situações de assédio moral no trabalho. A doutrina é assente em enumerar alguns efeitos e danos à saúde do assediado que estabelecem implicações médicolegais e previdenciárias. Neste sentido, o diagnóstico de doença relacionada ao trabalho em trabalhador segurado pelo Seguro Acidente do Trabalho (SAT) da Previdência Social obriga que seja aberta uma Comunicação de Acidente do Trabalho (CAT), garantindo os direitos previdenciários ao trabalhador.

Glina DMR, Garbin A de C. Psychological harrassment at work conceptual, legal and preventive aspects. Saúde, Ética \& Justiça, São Paulo. 2005;10(1/2):38-47.

ABSTRACT: Objective: Discuss conceptual, legal and preventive aspects of bullying at work. Methodology: A survey of national scientific publications about bullying at work from the legal view point was performed in 2004: books, articles published in journals indexed or not on SciELO and Lilacs in the period ranging from 2000 until 2004, laws and proffered sentences. Publications from the World Health Organization, International Organization of Work, European Agency for Health and Safety at Work among others provided information on conceptual and preventive aspects of bullying at work. Results e discussion: There is not a single consensual definition of bullying at work. Bullying can be vertical or horizontal. It is a continued violence, which aims to exclude the victim from work. Work situations which favor bullying at work include: management style, problems related to work organization and those resulting from the flexibilization of production. Bullying at work can cause or contribute to many health disorders. The most common diagnosis are depression and anxiety disorders, but also adjustment disorder and post-traumatic stress disorder can happen. The legal doctrine relates bullying at work to the theory of civil responsibility, to material damage as well as to moral damage. In the Federal sphere there are law projects being analyzed at the National Congress, aiming to regulate the bullying at work in criminal law. Other law projects on bullying at work refer to public workers and the Law of Public Licitations. Various laws were promulgated on the municipal and state spheres but they can be applied only to public institutions. Moreover, they refer only to vertical bullying at work (from the chief to the subordinate) Prevention of bullying at work begins with the identification of work factors that can contribute to bullying at work. To be effective, prevention should be based on the participation and cooperation of all the actors. Prevention can be primary, secondary or tertiary.

KEY WORDS: Social behavior/prevention \& control. Working conditions. Working environment/legislation \& jurisprudence. Working environment/psychology. Workplace/psychology. Moral damage. Damage liability. Work/ psychology. Stress, psychological. Environmental health/ethics.

\section{REFERÊNCIAS}

1. Acórdão. Rev. Ltr, São Paulo. 2002;66(10)1237-40.

2. Barreto M. Uma jornada de humilhações [dissertação]. São Paulo: Estudos Pós-graduados em Psicologia Social, Pontifícia Universidade Católica de São Paulo; 2000.

3. Brasil. Consolidação das leis do trabalho. 29a ed. São Paulo: Saraiva; 2002.

4. Brasil. Constituição da República Federativa do Brasil. 31a ed. São Paulo: Saraiva; 2003.

5. Casillo J. Dano à pessoa e sua indenização. São
Paulo: Revista dos Tribunais; 1987 apud Silva L de PP. A reparação do dano moral no direito do trabalho. São Paulo: LTr; 2004.

6. Cassito MG, Gilioli R, Fingerhut MA, Kortum-Margot EG. Raising awareness of psychological harrassment at work: advice to health professionals, decision makers, managers, human resources directors, legal community, unions and workers. Geneva: World Health Organization; 2003. (Protecting Workers' Health Serie n. 4). 
Glina DMR, Garbin A de C. Assédio moral no trabalho: aspectos conceituais, jurídicos e preventivos.

7. Di Martino V. Workplace violence in the health sector - country case studies Brazil, Bulgaria, Lebanon, Portugal, South Africa, Thailand, plus an Australian study: synthesis report ILO/ICN/WHO/PSI Joint Programme on Workplace Violence in the Health Sector. Geneva; 2002.

8. European Agency for Safety and Health at Work. Bullying at work. Facts 23. Bilbao; 2002.

9. Hirigoyen MF. Mal-estar no trabalho: redefinindo o assédio moral. Rio de Janeiro: Bertrand Brasil; 2002.

10. Legislação Federal, Estadual e Municipal. Disponível em: http://www.assediomoral.org.br.

11. Leymann $\mathrm{H}$. Mobbing, psychoterror am Arbeitsplatz und wie man sich dagegen wehren kann. Rowholt: Reinbeck bei Hamburg; 1993.
12. Menezes CAC. Assédio moral. Rev. TST, Brasília, 2002;68(3):189-95.

13. Organização Internacional do Trabalho - OIT. Genebra; 2003.

14. Paoli P, Merllié D. Third European survey on working conditions 2000. Dublin: European Foundation for the Improvement of Living and Working Conditions; 2001.

15. Scott MJ, Stradling SG. Post-traumatic stress disorder without the trauma. Br J Clin Psychol. 1994;33:71-4.

16. Yamada D. Workplace bullying and the law, towards a transnational consensus? In: Einarsen S, Hoel H, Zapf $D$, Cooper CL. Bullying and emotional abuse in the workplace. International perspectives in research and practice (399-400). London: Taylor and Francis; 2003. 